\title{
The time course of semantic and syntactic processing in Chinese sentence comprehension: Evidence from eye movements
}

\author{
JiNMIAN YANG \\ South China Normal University, Guangzhou, China \\ and University of Massachusetts, Amherst, Massachusetts \\ SUIPING WANG \\ South China Normal University, Guangzhou, China \\ Hsuan-Chin Chen \\ Chinese University of Hong Kong, Hong Kong, China \\ AND \\ KeITH RAYNER \\ University of California, San Diego, La Jolla, California
}

\begin{abstract}
In the present study, we examined the time course of semantic and syntactic processing when Chinese is read. Readers' eye movements were monitored, and the relation between a single-character critical word and the sentence context was manipulated such that three kinds of sentences were developed: (1) congruent, (2) those with a semantic violation, and (3) those with both a semantic and a syntactic violation. The eye movement data showed that the first-pass reading times were significantly longer for the target region in the two violation conditions than in the congruent condition. Moreover, the semantic + syntactic violation caused more severe disruption than did the pure semantic violation, as reflected by longer first-pass reading times for the target region and by longer go-past times for the target region and posttarget region in the former than in the latter condition. These results suggest that the effects of, at least, a semantic violation can be detected immediately by Chinese readers and that the processing of syntactic and semantic information is distinct in both first-pass and second-pass reading.
\end{abstract}

Reading comprehension involves different levels of complex cognitive processes. Besides orthographic, phonological, and semantic processing of individual words, readers also have to build up a coherent meaning representation through integrating the semantic properties of each word according to certain syntactic rules. So far, most evidence from studies of alphabetic languages appears to support the view that readers start all levels of processing in an immediate manner, including the higher order processes of semantic integration and syntactic analysis (Just \& Carpenter, 1980). For example, studies in which ambiguous words have been used have indicated that context exerts an immediate influence on word recognition (Duffy, Morris, \& Rayner, 1988; Kambe, Rayner, \& Duffy, 2001; Rayner, Cook, Juhasz, \& Frazier, 2006; Rayner \& Duffy, 1986; Rayner \& Frazier, 1989; Sereno, O’Donnell, \& Rayner, 2006). Moreover, evidence from behavioral and event-related potential (ERP) studies has suggested that readers detect immediately whether a word is semantically congruent with the context or not (Braze, Shankweiler, Ni,
\& Palumbo, 2002; Rayner, Warren, Juhasz, \& Liversedge, 2004; Rösler, Pütz, Friederici, \& Hahne, 1993; Van Berkum, Hagoort, \& Brown, 1999). In addition, garden path effects, which strongly support the notion that syntactic analysis begins very rapidly, have been observed in many studies (Bader \& Lasser, 1994; Crocker, 1994; Frazier \& Rayner, 1982; Sturt \& Crocker, 1996).

Although the results of a number of studies have suggested that the processing of both syntactic and semantic information occurs quickly and online, the relative time course of such processes and their interplay within the language processor is still not clear. To investigate this issue, the violation paradigm has often been used. The basic manipulation is to change a critical word in a sentence/text so as to introduce an anomaly. By observing and comparing the normal reading patterns and the patterns of disruptions caused by different types of anomalies on word viewing times, researchers can infer how and when the information that caused the anomaly was processed by readers (Chen, 1992, 1999; Danks, Bohn, \& Fears, 1983; Rayner

S. Wang, suipingscnu@263.net 
et al., 2004). With this paradigm, studies from alphabetic languages have demonstrated that syntactic and semantic processing differ from each other in time course, with the former being initiated earlier than the latter (Braze et al., 2002; McElree \& Griffith, 1995). For example, Braze et al. recorded eye movements while readers read sentences that differed by a single word, making the sentence syntactically anomalous (but understandable), pragmatically anomalous, or nonanomalous (control sentences). Results showed that syntactic anomalies manifested their effects right at the target verb, whereas for pragmatic anomaly, the effects were not apparent until the word after the target verb. Moreover, evidence from some ERP research has also supported the view that syntactic processing may be initiated very early, independently of semantic constraints and task requirements (Friederici, Pfeifer, \& Hahne, 1993; Gunter, Stowe, \& Mulder, 1997; Hahne \& Friederici, 2002).

However, it is worth noting that most studies on the relative timing of semantic and syntactic processing have been conducted with alphabetic languages. Less is known about this issue with respect to the reading of Chinese, a script used by nearly a quarter of the world's population (Chen \& Juola, 1982; Chen \& Shu, 2001; Chen \& Zhou, 1999). Since Chinese differs in many important aspects from alphabetic languages, such as English, it is not obvious that the results obtained from English can be applied to Chinese. Indeed, there is behavioral and neural evidence to show that language-specific processes are involved in processing alphabetic and nonalphabetic languages (e.g., Chen \& Juola, 1982; Cheung, Chen, Lai, Wong, \& Hills, 2001; Cutler \& Otake, 1994; Feng, Miller, Shu, \& Zhang, 2001; Gandour et al., 2002; Schirmer, Tang, Penney, Gunter, \& Chen, 2005). Hence, the study to be reported was designed to explore whether the relative time course of semantic and syntactic processing found in alphabetic languages can also account for reading comprehension in a distinctively different orthography - namely, logographic Chinese.

Unlike in English (and other alphabetic writing systems), ${ }^{1}$ the basic perceptual units of Chinese are often assumed to be characters rather than words. Since a Chinese word can be made up of one character or several, a character can be a single-character word or a morpheme of a multiple-character word, with a totally different meaning in these two situations. Therefore, the meaning of Chinese characters is often less precise and highly variable. Furthermore, given that there are no explicit markers between words in written Chinese (the spaces between characters and words are identical), Chinese readers have to rely largely on context to tell whether a character is itself a word (or just a constituent morpheme of a multiplecharacter word) and to acquire the proper meaning of it (Chao, 1968; Chen, 1996, 1999).

The grammatical properties of Chinese words are also very vague, because words in Chinese do not generally have explicit markers or inflectional indicators, such as lexical categories, number, tense, or other aspects, to specify different types of syntactic information. For example, in the following sentences, 1a. 他(he) 准备(is going to)下课后(after class)去 打篮球(play basketball) [he is going to play basketball after the class]

1b. 他(he) 昨天(yesterday)下课后(after class)去打 篮球了 (play basketball) [he played basketball after the class yesterday],

there is no inflection with the verb 打 (play) no matter whether this action is going to happen or has already happened. Thus, readers have to depend on the context to determine its tense. Furthermore, the lack of inflectional changes and intrasentence concordance rules (e.g., subject-verb agreement) means that readers are not able to rely on explicit morphological cues to determine the exact syntactic role of a word that belongs to more than one word category; for example, 调查(investigation/ investigate) can be a verb or a noun. Consequently, syntactic analysis of a critical word (CW) in Chinese must be based on the context (information provided by words prior to and/or following the $\mathrm{CW}$ ), and it is hard for readers to determine whether a sentence is grammatically correct or not without knowing its meaning.

Given that semantic and syntactic properties are highly context dependent, it has been argued that higher level mental processes in Chinese comprehension would not be expected to function in an immediate manner (Aaronson \& Ferres, 1986) and that a delayed comprehension strategy would be more suitable for building up a coherent representation during reading, because it can maximize the amount of information available and minimize the ambiguities encountered. Furthermore, regarding the issue of relative timing of syntactic and semantic processing, some researchers (see Zhang, 1997a, 1997b) have argued that Chinese readers do not have as clear an idea about syntactic properties as do English readers and that syntactic processing cannot be dissociated from semantic processing, because semantic information is often needed to determine whether a Chinese word fits the sentence grammatically. In contrast, other researchers (see Fan, 2007; Shi, 2000) have insisted that there are rigorous syntactic rules in Chinese independent of semantics, even though such rules are much more flexible and opaque. In this view, it is possible to dissociate syntactic processing from semantic processing.

Using the violation paradigm, Chen (1999) first investigated the time course of syntactic and semantic processing in the reading of Chinese. He pointed out that although a syntactic violation condition can be used to explore the processing of syntactic information in studies of alphabetic languages, it is better to use a semantic + syntactic violation condition to study Chinese, because syntax and semantics are closely interrelated in Chinese and, thus, most syntactic violations will always severely disrupt semantic processing. Hence, in his study, he recorded and analyzed the patterns of disruptions caused by different types of violations (i.e., lexical, semantic, and syntactic + semantic violations) on character-viewing times. The results showed that lexical disruption appeared exactly at the $\mathrm{CW}$, whereas semantic and semantic+syntactic violations showed patterns of delayed disruption at 
the $\mathrm{CW}+1$ position. In addition, no significant difference was found between the semantic and the semantic + syntactic violations. These results seem to provide support for the hypotheses that high-level information is not processed in an immediate manner and syntactic processing cannot be dissociated from semantic processing.

However, the slightly delayed effect of semantic and semantic + syntactic violations in Chen's (1999) study may have resulted from the experimental paradigm: the selfpaced reading procedure. Indeed, some researchers (see Rayner \& Pollatsek, 1989) have argued that this type of text display procedure may induce readers to employ buffering strategies. Specifically, since readers cannot press the response button as quickly as they can comprehend, especially if the text is presented word by word, they may press the key rapidly and then wait until the end of a clause or a unit to process the material. Hence, data collected via the self-paced reading paradigm should be interpreted with caution (Danks, 1986; Magliano, Graesser, Eymard, Haberlandt, \& Gholson, 1993). Moreover, the insignificant difference between the semantic violation and the syntactic + semantic violation in Chen's (1999) study may also have resulted from the insensitivity of the experimental paradigm.

More recently, using the violation paradigm, researchers have investigated ERP correlates of semantic and syntactic violations (Ye, Luo, Friederici, \& Zhou, 2006; Yu \& Zhang, 2008). Ye et al. found that syntactic processing was different from semantic processing in auditory comprehension of Chinese sentences. However, contrary to Chen's (1999) view that syntactic violations will always severely disrupt semantic processing in Chinese, they created a so-called pure syntactic violation by eliminating the object-noun phrase (NP) from a preposition-object phrase structure. Therefore, they had four types of sentences: correct, semantically incorrect, syntactically incorrect, or both semantically and syntactically incorrect. Their results suggested that syntactic processes appeared earlier (at about $50 \mathrm{msec}$ ) than semantic processes (at around $150 \mathrm{msec}$ ), and they were independent from each other in the early time window $(150-250 \mathrm{msec})$ but interacted in a later processing phase $(250-400 \mathrm{msec})$. Moreover, a broadly distributed negativity occurring during the N400 latency range was observed in the three violation conditions, which was thought to reflect thematic integration processes in the sentence-final position. However, a problem with their study is that the syntactically incorrect condition could also cause semantic disruption, since a noun was missing from a preposition-object phrase structure. Thus, the semantic disruption caused by a missing noun in the syntactic violation condition could be more severe than that in the semantically incorrect condition (where the violation would be caused by an inappropriate noun). In other words, the earlier effects observed in the syntactically incorrect condition may be due to a more severe semantic violation, rather than to the inappropriate syntactic structure.

Indeed, using a logic similar to that in Chen's (1999) study in manipulating semantic and semantic + syntactic violations (i.e., there were three conditions: correct, se- mantic violation, and semantic + syntactic violation), and matching the degree of semantic violation between the semantic violation and the semantic + syntactic violation conditions, Yu and Zhang (2008) found that the effects of a semantic + syntactic violation did not appear earlier than the effect of a pure semantic violation. Whereas pure semantic violations elicited a centro-parietal negativity, combined violations elicited a broadly distributed, but centro-parietally focused negativity, in both the 300 to 500 -msec window and the following P600. However, as compared with pure semantic violations, combined violations triggered a larger negativity at $\mathrm{Fz}$ and the lateral fronto-central electrodes.

Obviously, the effects of semantic and syntactic violations were more online in the EEG studies than in Chen's (1999). These effects may have been due to the high temporal resolution of the ERP technique. However, it should also be noted that although ERP recording can reveal fine temporal details of brain activity in response to semantic and syntactic manipulations, in studies of sentence or text reading, the stimulus is usually presented at a very slow rate (often 400-600 msec per word) that does not approximate real-world uptake of written language. Hence, in the present experiment, eye tracking, which yields an online measure of processing (Rayner, 1998), was used to further explore the time course of semantic and syntactic processing during the reading of Chinese.

We explored two questions: (1) Does syntactic and semantic processing occur immediately, and (2) can they be separated from each other during online reading? As in Chen's (1999) study, a CW (a single-character word ${ }^{2}$ ) in a sentence was altered to form three kinds of violation conditions: congruent (CON), a semantic violation (SEM), and both a semantic and a syntactic violation (SEM+SYN). Furthermore, as in Yu and Zhang's (2008) study, an improvement was made on Chen's (1999) studies such that the degree of semantic violation of the SEM and SEM + SYN conditions was closely matched via rating studies. Therefore, any possible differences in eye movement patterns between the two violation conditions should be attributed to syntactic processing, instead of differing degrees of semantic violation across the conditions. Thus, we should be able to infer the time course of semantic and syntactic processing. If violation effects in the SEM + SYN condition are different from those in the SEM condition, the differences should be reflected in two ways. First, the violation effect may appear in different locations in the sentence. For example, if violation effects due to the SEM+SYN condition appear in the character prior to (or following) the character where semantic violation effects are evident, we can infer that syntactic processing starts earlier (or later) than semantic processing. Second, violation effects in one condition may be stronger than those in the other condition even when they occur at the same position in the sentence. For example, if violation effects are evident right on the $\mathrm{CW}$ (which also suggests immediate processing), with longer fixation times in the SEM + SYN condition than in the SEM condition, we can infer that syntactic processing can be distinguished from semantic processing. 


\section{METHOD}

\section{Participants}

Thirty-six undergraduate students at the South China Normal University participated in the experiment for course credit. They all had normal or corrected-to-normal vision and were native speakers of Chinese.

\section{Materials}

There were 39 experimental sentence frames; ${ }^{3}$ each sentence frame contained a single-character $\mathrm{CW}$. By manipulating the relation between the $\mathrm{CW}$ and the sentence context, three kinds of sentences were developed: CON, SEM, and SEM+SYN. Examples are shown in Table 1, and the full set of sentences is provided in the Appendix. The CW 帽 (a noun that means hats) in the CON Sentence 2A was both semantically and syntactically appropriate for the sentence context. In the SEM Sentence $2 \mathrm{~B}$, the CW 狼 (a noun that means wolves) maintained the syntactic property of the $\mathrm{CON} \mathrm{CW}$ as being a noun but was semantically inappropriate for the context. And in the SEM+SYN Sentence $2 \mathrm{C}$, the CW 割 (a verb that means cut) yielded both a syntactic and a semantic violation in the sentence context. Note that all of the CWs in this condition can be used as verbs only when they are presented in isolation. Given that context plays an important role in determining word category, two norming studies (presented below) were used to ensure that this condition really introduced a syntactic violation. For each sentence frame, the three kinds of CWs were located at the same position in the sentence: They were in the middle of the sentence, at least 3 characters away from the beginning and 10 characters away from the end of the sentence, so that we could examine how many characters the effect of violation would spill over to.

The lexical properties of the $\mathrm{CW}$ were closely matched among the three conditions. The number of strokes averaged 10.0 in all conditions. Mean word frequency, in units of occurrence per million, was $122(S D=110)$ for the CON condition, $140(S D=131)$ for the SEM condition, and $119(S D=199)$ for the SEM+SYN condition $(F<1) .{ }^{4}$ In addition, the three $\mathrm{CWs}$ associated with each sentence were all of the same spatial structure (e.g., left-right or top-bottom) but differed in phonological features.

Three material sets were created for the experiment, each containing 39 experimental sentences and 57 filler sentences. The experimental stimuli in each set included 13 sentences in the CON version, 13 in the SEM version, and 13 in the SEM+SYN version. Each version of the experimental sentences appeared once across the three sets.

\section{Rating Studies}

As was discussed in the introduction, the grammatical properties of Chinese words are very vague, and identification of them is highly context dependent. Thus, care was taken in developing the experimental sentences to ensure that sufficient information would be provided by the prior context for the readers to infer the word category of the $\mathrm{CW}$ before seeing it. Therefore, the readers should have experienced a syntactic violation when the word category was different from their expectation. To make sure that this manipulation was effective, two rating studies regarding the word category of the CWs were conducted.

In the first word category rating study, 10 Chinese undergraduate students were given the first part of each experimental sentence (from the beginning to one word before the $\mathrm{CW}$ ) and were asked to predict the word category of the next word (the CW) in the sentence. They agreed $92 \%$ of the time that the $\mathrm{CW}$ should be a noun. In the second word category rating study, another 21 Chinese undergraduate students were given the first part of the experimental sentence up to (and including) the $\mathrm{CW}$, and were asked to decide the word category of the CW. Experimental materials were divided into three lists. Each consisted of 16 sentences in the CON, SEM, and SEM + SYN conditions. The participants agreed $98 \%$ of the time that the $\mathrm{CW}$ was a noun in the CON condition, whereas $91 \%$ of the time they thought that it was a noun in the SEM condition and $81 \%$ of the time they thought that it was a verb (and only $9 \%$ of the time a noun) in the SEM+SYN condition. The results suggested that the readers had a strong expectation that the correct $\mathrm{CW}$ was a noun on the basis of the sentence context prior to the CW. Also, the ratings ensured that our manipulation of the word category of the CWs in the SEM and the SEM+SYN conditions was valid (although the percentage of agreement in the SEM+SYN condition was lower than that in the SEM condition).

Given that the double-violation condition not only includes a syntactic violation (i.e., word category violation), but also contains a semantic violation (i.e., the meaning of the $\mathrm{CW}$ is not suitable for the sentence context), two understandability rating studies were conducted to ensure that the degree of semantic violation between the SEM and SEM+SYN conditions was matched, as well as to ensure that the experimental sentence was congruent or incongruent with respect to the $\mathrm{CW}$ manipulation. In the first rating study, 24 participants were presented with each of the complete experimental sentences and were asked to rate the understandability of the sentence on a 4-point scale (where $1=$ not understandable; $4=$ very understandable). The materials were divided into three lists, each of which consisted of 16 sentences in each of the three conditions. The participants were assigned to one of these lists. The results showed that there was a significant effect of violation on understandability $\left[F_{1}(2,46)=88.73, p<.001 ; F_{2}(2,76)=350.48, p<.001\right]$. Pairwise $t$ tests indicated that understandability in the CON condition $(M=$ $3.08, S D=0.32$ ) was significantly higher than that in the SEM condition $(M=1.55, S D=0.30)\left[t_{1}(23)=9.56, p<.001 ; t_{2}(38)=\right.$ $21.68, p<.001]$ or the SEM+SYN condition $(M=1.62, S D=$

Table 1

Examples of a Stimulus Sentence Used in the Experiment

Congruent (CON):

$2 \mathrm{~A}$. 冬天给/(1)孩子/(2)戴帽*/(3)可以/(4)保护/(5)头部/(6)不易/(7)受凉。

Winter, giving/(1)children/(2)wear hats/(3)can/(4)protect/(5)head/(6)not easy/(7)catch a cold.

In winter, wearing hats can protect children from catching a cold.

Semantic violation (SEM):

2B. 冬天给/(1)孩子/(2)戴 狼*/(3)可以/(4)保护/(5)头部/(6)不易/(7)受凉。

Winter, giving/(1)children/(2)wear wolves/(3)can/(4)protect/(5)head/(6)not easy/(7)catch a cold.

In winter, wearing wolves can protect children from catching a cold.

Semantic + syntactic violation $(\mathrm{SEM}+\mathrm{SYN})$ :

2C. 冬天给/(1)孩子/(2)戴割*/(3)可以/(4)保护/(5)头部/(6)不易/(7)受凉。

Winter, giving/(1)children/(2)wear cut/(3)can/(4)protect/(5)head/(6)not easy/(7)catch a cold. In winter, wearing cut can protect children from catching a cold.

Note- ${ }^{*}$ The critical word; (1) the region T-1; (2) the target region T; (3) the first posttarget region $\mathrm{T}+1 ;$; 4 ) the second posttarget region $\mathrm{T}+2 ;(5)$ the third posttarget region $\mathrm{T}+3$; (6) the fourth posttarget region $\mathrm{T}+4 ;(7)$ the last region of the sentence. 
0.27) $\left[t_{1}(23)=9.80, p<.001 ; t_{2}(38)=21.83, p<.001\right]$. There was no significant difference between the SEM and SEM+SYN conditions $(p s>.2)$. Furthermore, since a Chinese word can consist of one or several characters, the possibility exists that readers may consider single-character CWs as the first character of a multiplecharacter word and delay attempting to understand the CW until the next character or several characters are available. ${ }^{5}$ To examine this possibility, 24 participants were presented with the first part of the sentences up to (and including) the $\mathrm{CW}$ and were asked to rate the understandability of the sentence (assuming that the sentence will end with a second part) on a 4-point scale (where $1=$ not understandable; $4=$ very understandable $)$. If readers think that the $\mathrm{CW}$ is the first character of a multiple-character word (and that the following information will form a suitable word for the sentence), the violation effect should be reduced or even disappear. However, the results showed that there was a significant effect of violation on understandability $\left[F_{1}(2,46)=72.77, p<.001 ; F_{2}(2,76)=129.97\right.$, $p<.001]$. Pairwise $t$ tests indicated that understandability in the CON condition $(M=3.19, S D=0.49)$ was significantly higher than that in the SEM condition $(M=1.89, S D=0.40)\left[t_{1}(23)=\right.$ $\left.9.27, p<.001 ; t_{2}(38)=11.70, p<.001\right]$ and in the SEM + SYN condition $(M=1.90, S D=0.33)\left[t_{1}(23)=8.69, p<.001 ; t_{2}(38)=\right.$ $14.75, p<.001]$. No significant difference was found between the SEM and SEM + SYN conditions $(p s>.5)$. The results of this rating study ensured that the possibility that the readers might anticipate that information following the $\mathrm{CW}$ would eliminate the violation effects in the two violation conditions was quite small; furthermore, this possibility was comparable between the SEM and SEM+SYN conditions.

All the participants enrolled in the four rating studies were from the same participant pool. They did not participate in the main experiment, and they participated in only one of these rating studies. Together, the rating studies ensured that our manipulation of SEM and SEM + SYN violations was valid and that the chance that the readers might detect these violations immediately was maximized.

\begin{abstract}
Apparatus
An SR Eyelink 1000 eyetracking system was used to track eye movements at the rate of $1000 \mathrm{~Hz}$. The eyetracker monitored movements of the right eye, although viewing was binocular. A Dell 19-in. SVGA monitor was used to display the stimuli. All the stimuli were presented in white on a black background on the computer monitor. All the characters were printed in Kai-Ti font. The size of each character was $0.95 \times 0.95 \mathrm{~cm}^{2}$, with $0.25 \mathrm{~cm}$ between individual characters. Each character subtended approximately $0.8^{\circ}$ of visual angle with the participant's eyes being $71 \mathrm{~cm}$ away from the monitor. For each experimental trial, the sentence always appeared in the center of the screen, and the $\mathrm{CW}$ also appeared in the middle of the sentence.
\end{abstract}

\section{Procedure}

Prior to beginning the experiment, the participants were given the experimental instructions. They were randomly assigned to one of three stimulus sets and were tested individually. The experiment consisted of a calibration phase and an experimental phase. In the calibration phase, each participant performed a 3-point calibration procedure to make sure that the eyetracker recordings were accurate. The experimental phase then followed.

At the beginning of the experimental phase, the participants were told to read each sentence carefully for comprehension. Before reading each sentence, they were first asked to fixate on a dot at the middle left corner of the computer screen that indicated the position of the first character of the sentence. Once they fixated on the dot, the sentence was displayed. The participants read each sentence at their own pace and then pressed a button to terminate the end of the trial. One third of the sentences were immediately followed by a true-false comprehension question to ensure that the participants were not merely skimming the sentences. The participants answered the question on the basis of the information from the previous sen- tence by pressing an appropriate button. The answer to a question of an experimental sentence was identical in the CON, SEM, and SEM + SYN conditions. Each participant read the 39 experimental and 57 filler sentences in a random order; the whole experiment lasted about $30 \mathrm{~min}$. Six practice sentences were presented at the beginning of the experiment to familiarize the participants with the procedure. The participants were informed that they could take a break whenever they needed one.

\section{RESULTS}

All the participants scored $75 \%$ or better in response to the questions, averaging 94\%. Fixations less than $60 \mathrm{msec}$ or greater than $600 \mathrm{msec}$ were eliminated from the analyses. Thus, $6.3 \%$ of the data were lost, including track losses.

Two sets of analyses were carried out to analyze the eye movement data for the experimental sentences. The first set was based on individual characters and included the $\mathrm{CW}$, two characters before it $(\mathrm{CW}-2$ and $\mathrm{CW}-1)$ and three characters after it $(\mathrm{CW}+1, \mathrm{CW}+2$, and $\mathrm{CW}+3)$. The second set was based on regions wherein every two characters of interest were combined. Specifically, the sentences were divided into seven regions: a pretarget region $\mathrm{T}-1$ (including $\mathrm{CW}-3$ and $\mathrm{CW}-2$ ), a target region $\mathrm{T}$ (including $\mathrm{CW}-1$ and $\mathrm{CW}){ }^{6}$ a first posttarget region $\mathrm{T}+1$ (including $\mathrm{CW}+1$ and $\mathrm{CW}+2$ ), a second posttarget region $\mathrm{T}+2$ (including $\mathrm{CW}+3$ and $\mathrm{CW}+4$ ), a third posttarget region $\mathrm{T}+3$, a fourth posttarget region $\mathrm{T}+4$, and a last region LR (including the last two characters and the period). An illustration of the combination of characters is shown in Table 1. We included the regions prior to and following the $\mathrm{CW}$ in order to examine so-called parafovealon-foveal effects (Starr \& Rayner, 2001) and spillover effects of the violations, respectively. We will return to these two kinds of effects in reporting the results.

In each set of analyses, a number of eye movement measures (Rayner, 1998) reflecting first-pass processing (i.e., initial skipping probability, first-fixation duration, gaze duration/first-pass reading time) and later processing (i.e., second-pass reading time, go-past time, regressions in, regressions out, and total reading time) were computed as a function of the violation. Analyses were performed using a linear mixed-effects (lme) model specifying participants and items as crossed random effects. The advantage of such analyses is that they result in substantially less loss of statistical power in unbalanced designs than do traditional ANOVAs over participants and items (see Baayen, 2008; Baayen, Davidson, \& Bates, 2008). These analyses were carried out using the lmer4 package (Bates, Maechler, \& Dai, 2008) in $R$, an open-source programming language and environment for statistical computation ( $\mathrm{R}$ Development Core Team, 2008). We will report regression coefficients ( $b s$, effects relative to the intercept), standard errors (SEs), and $p$ values estimated using posterior distributions for model parameters obtained by Markov chain Monte Carlo sampling (Baayen, 2008; Baayen et al., 2008).

The major issues are the following: (1) Can Chinese readers detect semantic and/or syntactic violations immediately, and (2) can syntactic and semantic processing be separated from each other? To address these issues, two 
Table 2

\begin{tabular}{|c|c|c|c|c|c|c|c|c|c|c|c|}
\hline \multirow[b]{2}{*}{ osition } & \multirow[b]{2}{*}{ Violation } & \multicolumn{2}{|c|}{ SP } & \multicolumn{2}{|c|}{$\begin{array}{c}\text { FFD } \\
(\mathrm{msec})\end{array}$} & \multicolumn{2}{|c|}{$\begin{array}{c}\mathrm{GD} \\
(\mathrm{msec})\end{array}$} & \multicolumn{2}{|c|}{ Reg. Out } & \multicolumn{2}{|c|}{ Reg. In } \\
\hline & & $M$ & $\overline{S D}$ & $M$ & $\overline{S D}$ & $M$ & $\overline{S D}$ & $M$ & $S D$ & $M$ & $S D$ \\
\hline \multirow[t]{3}{*}{$C W-2$} & $\mathrm{CON}$ & .44 & .18 & 217 & 36 & 228 & 44 & 11.9 & 16.1 & 8.9 & \\
\hline & SEM & .42 & .17 & 221 & 31 & 226 & 31 & 10.1 & 13.3 & 13.5 & 12 \\
\hline & $\mathrm{SEM}+\mathrm{SYN}$ & .42 & .18 & 226 & 41 & 234 & 43 & 13.8 & 15.2 & 13.5 & 11. \\
\hline \multirow[t]{3}{*}{$\mathrm{CW}-1$} & $\mathrm{CON}$ & .40 & .20 & 237 & 35 & 247 & 37 & 11.5 & 16.4 & 9.4 & 8 \\
\hline & SEM & .38 & .23 & 245 & 41 & 263 & 49 & 7.5 & 12.1 & 26.1 & 19.0 \\
\hline & $\mathrm{SEM}+\mathrm{SYN}$ & .34 & .18 & 243 & 41 & 270 & 65 & 9.2 & 10.1 & 29.3 & 18 \\
\hline \multirow{3}{*}{ CW } & $\mathrm{CON}$ & .33 & .22 & 245 & 37 & 254 & 41 & 11.4 & 13.8 & 9.1 & 11 \\
\hline & SEM & .32 & .18 & 286 & 43 & 325 & 53 & 16.8 & 15.5 & 24.7 & 16 \\
\hline & $\mathrm{SEM}+\mathrm{SYN}$ & .29 & .16 & 285 & 40 & 336 & 55 & 20.9 & 16.1 & 30.8 & 15. \\
\hline \multirow[t]{3}{*}{$\mathrm{CW}+1$} & $\mathrm{CON}$ & .46 & .18 & 223 & 40 & 237 & 43 & 14.6 & 18.3 & 4.7 & 6. \\
\hline & SEM & .38 & .16 & 264 & 40 & 280 & 42 & 25.2 & 20.1 & 11.0 & 11 \\
\hline & $\mathrm{SEM}+\mathrm{SYN}$ & .37 & .16 & 257 & 48 & 276 & 49 & 36.5 & 21.0 & 15.1 & 15. \\
\hline \multirow[t]{3}{*}{$\mathrm{CW}+2$} & $\mathrm{CON}$ & .50 & .19 & 230 & 36 & 236 & 43 & 6.7 & 10.5 & 4.8 & \\
\hline & SEM & .43 & .14 & 243 & 49 & 252 & 54 & 16.4 & 17.5 & 6.7 & \\
\hline & $\mathrm{SEM}+\mathrm{SYN}$ & .42 & .18 & 261 & 47 & 278 & 63 & 21.5 & 17.7 & 8.8 & \\
\hline \multirow[t]{3}{*}{$\mathrm{CW}+3$} & $\mathrm{CON}$ & .44 & .16 & 231 & 35 & 234 & 37 & 3.7 & 6.9 & 5.6 & 8. \\
\hline & SEM & .48 & .17 & 248 & 48 & 257 & 48 & 12.3 & 14.2 & 6.7 & \\
\hline & $\mathrm{SEM}+\mathrm{SYN}$ & .44 & .16 & 242 & 44 & 247 & 48 & 14.2 & 13.9 & 4.1 & 8. \\
\hline
\end{tabular}

Note-CON, congruent; SEM, semantic violation; SEM+SYN, semantic + syntactic violation.

contrasts were set up: (1) CON versus SEM and (2) SEM versus SEM+SYN.7 We will report the eye movement measures reflecting the first-pass and later processing separately below.

\section{First-Pass Processing}

\section{Character-Based Analysis}

First-fixation duration (the time that the eyes initially fixate on the character, regardless of the number of total fixations on the character) and gaze duration (the sum of all fixations on a character before the eyes move to another character), which are sensitive online measures of processing (Birch \& Rayner, 1997; Ehrlich \& Rayner, 1983; Rayner, 1998), revealed a significant violation effect from $\mathrm{CW}$ to $\mathrm{CW}+3$. Moreover, there was a significant effect in gaze duration (but not first-fixation duration) for $\mathrm{CW}-1$. Specifically, the readers fixated longer in the SEM and SEM+SYN conditions than in the CON condition. However, there was no significant difference between the two kinds of violations on these characters, with the exception of $\mathrm{CW}+2$ (see Table 2). Moreover, the readers skipped less in the two violation conditions than in the CON condition, although this difference was significant only for $\mathrm{CW}+1$.

Although the character-based reading time analysis is informative, we will not report the results in detail, because (1) there was considerable missing data, due to the high skipping probability for individual Chinese characters (about .40, for a similar finding; see Chen, Song, Lau, Wong, \& Tang, 2003; Wong \& Chen, 1999; Wang, Chen, Yang, \& Mo, 2008), and (2) the pattern in the characterbased analysis was similar to that in the region-based analysis, and the effects were generally more robust in the latter analysis. However, it is worth noting the effect in gaze duration for $\mathrm{CW}-1$ [i.e., the $\mathrm{SEM}$ condition yielded longer fixation times than did the CON condition $(b=$ $18.80, S E=9.48, p<.05$ ), whereas there was no significant difference between the SEM and SEM + SYN conditions $(p>.6)$ ] because it may suggest that the characteristics of the character/word to the right of fixation exerted an influence on the processing of the currently fixated character/word (a parafoveal-on-foveal effect). Although there is controversy concerning the validity of lexical parafoveal-on-foveal effects in the reading of English (see Rayner \& Juhasz, 2004; Rayner, White, Kambe, Miller, \& Liversedge, 2003; Starr \& Rayner, 2001), there is some evidence for this effect in Chinese (see Yang, Wang, $\mathrm{Xu}$, \& Rayner, 2009). The effect of violation on $\mathrm{CW}-1$ in the present study seems to suggest that there are lexical parafoveal-on-foveal effects in reading Chinese. However, it is difficult to determine whether this effect was due to semantic processing or occurred because of mislocalized fixations. In alphabetic writing systems, it was demonstrated (Drieghe, Rayner, \& Pollatsek, 2008; Nuthmann, Engbert, \& Kliegl, 2005) that mislocalized fixations occurred wherein the reader intended to fixate on word $n$ but the saccade fell short of the target and the eyes landed on word $n-1$ instead. In such situations, the reader's eyes would be fixating word $n-1$, but word $n$ would be being processed. Further research specifically aimed at examining parafoveal-on-foveal effects (which the present study was not) is needed before we can conclude that the effects observed in the present experiment were due to semantic processing. 


\section{Region-Based Analysis}

We computed two standard measures typically used in region-based eye movement analyses (Rayner, 1998): the probability of initially skipping the region and first-pass reading time (i.e., the sum of all fixations on a region prior to moving to another region, similar to the gaze duration in the character-based analysis). The means for the different regions of the sentence are shown in Table 3.

Skipping. The region-based analysis reduced the initial skipping probability to about .10 for most of the regions, since the readers generally skipped less in the two violation conditions than in the CON condition. However, no contrasts were significant in any region $(p s>.1)$.

Fixation time. The first-pass reading times of the analyzed regions showed that the SEM condition yielded longer fixation times than did the $\mathrm{CON}$ condition in regions $\mathrm{T}$ $(b=99.06, S E=16.03, p<.001), \mathrm{T}+1(b=55.71, S E=$ 13.03, $p<.001)$, and T+2 $(b=23.36, S E=10.18, p<$ $.05)$. More important, the difference between the SEM and $\mathrm{SEM}+\mathrm{SYN}$ conditions was significant in region $\mathrm{T}(b=$ $34.85, S E=16.09, p<.05)$. No other significant effects were found $(p s>.2)$.

To sum up, eye movement measures reflecting initial processing (i.e., gaze duration in the character-based analysis and first-pass reading time in the region-based analysis) indicated that the SEM (also the SEM+SYN) violations can be detected right at the $\mathrm{CW} /$ target region. Moreover, the influence of the violation spilled over to subsequent processing, which was reflected by longer first-pass reading times in the $T+1$ and $T+2$ regions. Furthermore, first-pass reading times were longer in the SEM + SYN condition than in the SEM condition in the $\mathrm{T}$ region, which suggests that the introduction of a syntactic violation yielded more disruption than did the pure semantic violation.

\section{Later Processing}

Go-past time and second-pass reading time were computed for the characters and regions. Go-past time includes the amount of time that the reader looked at the $\mathrm{CW} /$ target region and any time spent rereading earlier parts of the sentence before moving ahead to inspect new parts of the sentence. Thus, it most likely reflects both lexical processing and integration processes, because the reader likely realized that there was some problem with the $\mathrm{CW} /$ target region and, thus, made a regression back to some earlier part of the sentence (Rayner et al., 2004). Second-pass reading time (which also reflects integration processes) includes the sum of all fixations on the character/region, except those made in first-pass reading. For completeness, we also computed total reading time, which includes all fixations on the character/region. Since the pattern of second-pass reading time was identical to that of go-past time, we will discuss only the go-past time and the total reading time.

The probability of regressions in and regressions out of individual characters will also be reported. These measures indicate where the readers encountered anomalies and where they looked back to try to integrate the anomalies into the sentence. We will report these two measures only for the character-based analysis, because some regressions from one character to another character within a region would not be counted in the region-based analysis. For example, in the $\mathrm{T}$ region with $\mathrm{CW}-1$ and $\mathrm{CW}$, when readers regressed back from $\mathrm{CW}$ to $\mathrm{CW}-1$, it would be considered a refixation of the same region, rather than a regression.

\section{Character-Based Analysis}

The effects of violation were evident in go-past time on characters $\mathrm{CW}$ to $\mathrm{CW}+3$, and in total reading time on

Table 3

Participant Means of Initial Skipping Probability (SP), First-Pass Reading Time (FPRT), Go-Past Time (GP), and Total Reading Times (TRT) As a Function of Congruency at Different Regions of the Experimental Sentences (With Standard Deviations)

\begin{tabular}{|c|c|c|c|c|c|c|c|c|c|}
\hline \multirow[b]{2}{*}{ Region } & \multirow[b]{2}{*}{ Violation } & \multicolumn{2}{|c|}{ SP } & \multicolumn{2}{|c|}{ FPRT } & \multicolumn{2}{|c|}{ GP } & \multicolumn{2}{|c|}{ TRT } \\
\hline & & $M$ & $S D$ & $M$ & $S D$ & $M$ & $S D$ & $M$ & $S D$ \\
\hline \multirow[t]{3}{*}{$\mathrm{T}-1$} & $\mathrm{CON}$ & .14 & .10 & 285 & 73 & 342 & 118 & 349 & 113 \\
\hline & SEM & .12 & .10 & 288 & 62 & 354 & 103 & 370 & 91 \\
\hline & $\mathrm{SEM}+\mathrm{SYN}$ & .15 & .12 & 284 & 56 & 339 & 97 & 363 & 93 \\
\hline \multirow[t]{3}{*}{$\mathrm{T}$} & $\mathrm{CON}$ & .05 & .06 & 340 & 88 & 402 & 126 & 420 & 120 \\
\hline & SEM & .05 & .07 & 436 & 120 & 505 & 190 & 622 & 196 \\
\hline & $\mathrm{SEM}+\mathrm{SYN}$ & .06 & .07 & 478 & 140 & 556 & 174 & 715 & 173 \\
\hline \multirow[t]{3}{*}{$\mathrm{T}+1$} & $\mathrm{CON}$ & .15 & .10 & 299 & 79 & 353 & 113 & 343 & 94 \\
\hline & SEM & .12 & .11 & 354 & 93 & 521 & 162 & 476 & 145 \\
\hline & $\mathrm{SEM}+\mathrm{SYN}$ & .10 & .08 & 352 & 85 & 622 & 212 & 527 & 146 \\
\hline \multirow[t]{3}{*}{$\mathrm{T}+2$} & $\mathrm{CON}$ & .11 & .08 & 284 & 61 & 300 & 69 & 326 & 98 \\
\hline & SEM & .09 & .08 & 304 & 70 & 385 & 118 & 371 & 102 \\
\hline & $\mathrm{SEM}+\mathrm{SYN}$ & .13 & .11 & 301 & 69 & 373 & 104 & 353 & 86 \\
\hline \multirow[t]{3}{*}{ LR } & $\mathrm{CON}$ & .22 & .14 & 291 & 87 & 449 & 207 & 311 & 102 \\
\hline & SEM & .21 & .13 & 311 & 85 & 555 & 414 & 340 & 108 \\
\hline & $\mathrm{SEM}+\mathrm{SYN}$ & .24 & .15 & 323 & 98 & 547 & 267 & 348 & 102 \\
\hline
\end{tabular}

Note-Reading times are in milliseconds. CON, congruent; SEM, semantic violation; $\mathrm{SEM}+\mathrm{SYN}$, semantic + syntactic violation. 
characters $\mathrm{CW}-1$ to $\mathrm{CW}+3$. Reading times were longer in the SEM and SEM+SYN conditions than in the CON condition. Moreover, differences between the two kinds of violations were significant in go-past time for $\mathrm{CW}, \mathrm{CW}+1$, and $\mathrm{CW}+2$ and in total reading time for $\mathrm{CW}$ and $\mathrm{CW}+2$. Again, since the pattern of these effects was identical to that in the regions with these characters, we will focus on these effects in the region-based analysis.

Regressions out. The readers were more likely to regress to an earlier portion of the sentence from $\mathrm{CW}(b=$ 5.92, $S E=2.89, p<.05), \mathrm{CW}+1(b=12.40, S E=3.60$, $p<.001), \mathrm{CW}+2(b=10.57, \mathrm{SE}=3.18, p<.001)$, and $\mathrm{CW}+3(b=7.10, S E=2.55, p<.01)$ in the SEM condition, as compared with the CON condition (see Table 2). Furthermore, the readers made more regressions in the $\mathrm{SEM}+\mathrm{SYN}$ condition than in the SEM condition from $\mathrm{CW}+1(b=12.10, \mathrm{SE}=2.10, p<.001)$, and $\mathrm{CW}+2$ $(b=5.34, S E=3.10, p=.08)$.

Regressions in. The readers were more likely to regress to $\mathrm{CW}-2(b=4.46, S E=2.11, p<.05), \mathrm{CW}-1$ $(b=16.48, S E=2.57, p<.001), \mathrm{CW}(b=15.72, S E=$ $2.55, p<.001)$, and $\mathrm{CW}+1(b=6.30, S E=1.91, p<$ .01 ) in the SEM condition than in the CON condition (see Table 2). Moreover, the readers more often regressed to $\mathrm{CW}(b=6.00, S E=2.56, p<.05)$ and $\mathrm{CW}+1(b=4.34$, $S E=1.91, p<.05)$ in the $\mathrm{SEM}+\mathrm{SYN}$ condition than in the SEM condition.

Together, the regressions-out and regressions-in results suggest that the violations caused at the $\mathrm{CW}$ were immediately evident and spilled over to the next three characters and that the readers were trying to use contextual information prior to the $\mathrm{CW}(\mathrm{CW}-2$ and $\mathrm{CW}-1)$ to resolve the anomalies. Moreover, these effects were larger at $\mathrm{CW}$ and $\mathrm{CW}+1$ in the SEM $+\mathrm{SYN}$ condition than in the SEM condition, suggesting that the readers encountered more difficulties in integrating the anomalies with the context.

\section{Region-Based Analysis}

For go-past times (see Table 3), the readers fixated longer in the SEM condition than in the CON condition in the $\mathrm{T}(b=106.86, S E=20.70, p<.001), \mathrm{T}+1(b=173.24$, $S E=24.59, p<.001), \mathrm{T}+2(b=90.25, S E=17.60, p<$ $.001)$, and LR $(b=91.56, S E=42.21, p<.05)$ regions. Furthermore, the readers fixated significantly longer in the SEM $+\mathrm{SYN}$ condition than in the SEM condition in the T $(b=44.74, S E=20.78, p<.05)$ and $\mathrm{T}+1(b=$ $104.55, S E=24.40, p<.001)$ regions, suggesting that they had more difficulty integrating the information in the former condition than in the latter condition. However, this effect did not appear in other regions ( $p$ s $>.1)$.

Total reading times (see Table 3 ) were significantly longer in the SEM condition than in the CON condition in the $\mathrm{T}(b=206.24, S E=21.46, p<.001), \mathrm{T}+1(b=133.16$, $S E=17.71, p<.001)$, and $\mathrm{T}+2(b=49.32, S E=13.95$, $p<.001)$ regions. Furthermore, total reading times were significantly longer in the SEM $+\mathrm{SYN}$ condition than in the SEM condition in the T $(b=88.16, S E=21.42, p<$ $.001)$ and $\mathrm{T}+1(b=54.50, S E=17.38, p<.01)$ regions. No other significant effects were found $(p s>.1)$.
In short, the eye movement measures reflecting later processing indicated that the readers encountered more difficulties in integrating the CWs in the violation conditions, since they had longer go-past times and total reading times in the SEM and SEM + SYN conditions than in the $\mathrm{CON}$ condition from $\mathrm{CW}$ to $\mathrm{CW}+3(\mathrm{~T}, \mathrm{~T}+1$, and $\mathrm{T}+2$ regions) and they were more likely to regress out from $\mathrm{CW}$ to $\mathrm{CW}+3$ to look back to an earlier portion of the sentence. Furthermore, there were significantly longer go-past times in the LR in the SEM and the SEM+SYN conditions than in the CON condition, indicating that some integration processing was conducted at the end of sentence. More important, a joint effect of the semantic and syntactic violation was larger than the pure semantic violation, since go-past times and total reading times in the $\mathrm{T}$ and $\mathrm{T}+1$ regions were longer in the $\mathrm{SEM}+\mathrm{SYN}$ condition than in the SEM condition. Also, the readers made more regressions out from $\mathrm{CW}+1$ and $\mathrm{CW}+2$ to an earlier portion of the sentence and were more likely to look back into $\mathrm{CW}$ and $\mathrm{CW}+1$ when they encountered anomalies in the SEM+SYN condition than in the SEM condition, suggesting that syntactic processing could be dissociated from semantic processing in the reading of Chinese.

\section{DISCUSSION}

Using the violation paradigm, the present study explored the time course of semantic and syntactic processing in Chinese. Participants' eye movements were monitored as they read sentences with a critical single-character word that was congruent in the sentence context or yielded a semantic violation or both a semantic and syntactic violation. The results showed that (1) both joint syntactic and semantic violations and pure semantic violations were detected immediately and (2) they can be separated from each other by eye movement measures that reflect initial and later processing. We will discuss these two points in detail below.

First, both the character-based analysis and the regionbased analysis showed that semantic + syntactic violations and pure semantic violations were detected immediately and yielded disruption effects right on the $\mathrm{CW} /$ target region. These effects were also evident for $\mathrm{CW}-1$, which may reflect a parafoveal-on-foveal effect but could be due to mislocated fixations. Moreover, the effect of the violation spilled over to the subsequent characters/regions, so that first-pass reading time in the posttarget $\mathrm{T}+1$ and $\mathrm{T}+2$ regions in the SEM and the SEM $+\mathrm{SYN}$ conditions was significantly longer than that in the $\mathrm{CON}$ condition. Note that these results are not consistent with the delayed hypothesis, wherein Chinese readers wait for more information after the $\mathrm{CW}$ to build up a coherent representation. Instead, they are in line with the idea that the higher level integration processes are initiated quite rapidly. Furthermore, these results imply that the readers were trying to use the contextual information to resolve the inconsistent information, since the violation effects were significant in go-past time, second-pass reading time, regressions out, 
and regressions in. In sum, with respect to the first question addressed by the present study, the results suggest that higher level integration starts immediately in the reading of Chinese, although its completion spills over to subsequent parts of the text.

Second, regarding the relative time course of semantic and semantic + syntactic processing, the violation effect in the SEM+SYN condition did not appear earlier than that in the SEM condition, since violation effects in these two conditions were first evident on the same character $(\mathrm{CW}-1)$. Since the difference between the SEM and $\mathrm{SEM}+\mathrm{SYN}$ conditions was not significant at $\mathrm{CW}-1$, it is possible that the effect at $\mathrm{CW}-1$ was due to the processing of inappropriate semantic meaning from the $\mathrm{CW}$ (a semantic parafoveal-on-foveal effect). In other words, semantic processing may start earlier than syntactic processing in Chinese. However, as was mentioned above, further studies are needed to test this possibility. What can be concluded from the present experiment is that syntactic processing is not initiated earlier than semantic processing in the reading of Chinese. This conclusion differs from those from studies involving the reading of alphabetic languages, wherein syntactic processing was initiated earlier than semantic processing (Boland, 1997; Braze et al., 2002; McElree \& Griffith, 1995). A possible reason for the difference between Chinese and alphabetic languages may lie in the fact that most alphabetic languages have some explicit markers to specify the word categories and the syntactic role played by words, through which readers can immediately understand the syntactic structure of a sentence even without knowing the meanings of the words in the sentence. However, in Chinese, a language with virtually no such markers for identifying grammatical functions, syntactic information can be inferred only from the semantic information and the sentence context.

In addition, differences between the SYN+SEM and SEM conditions appeared in first-pass reading time in the target region $\mathrm{T}$, indicating that the syntactic violation resulted in greater comprehension difficulties than did the semantic violation. Furthermore, differences between these two kinds of violations were evident in the go-past time in the target region $\mathrm{T}$ and posttarget region $\mathrm{T}+1$. It is probably the case that the readers were trying to reanalyze the sentence structure to solve the contradiction in the SEM and the SEM+SYN conditions in later processing, such as taking the incongruent $\mathrm{CW}$ as a modifier for a following congruent noun. However, it may have been harder for the readers to reanalyze the sentence structure when the target noun in the congruent condition was replaced by a verb in the SEM+SYN condition than when the target noun in the congruent condition was replaced by a noun in the SEM condition. Although it is not known for sure what causes the difference between the semantic and the semantic + syntactic conditions, our results clearly showed that these two kinds of processing can be discriminated by eye movement measures. These results are consistent with those of a functional neuroimaging study that demonstrated a dissociation between semantic and syntactic processes in the reading of Chinese sentences, using the same violation paradigm (Wang, Zhu, et al., 2008).
As compared with the SEM condition, the left inferior frontal area (BA 44) was more strongly activated in the SEM + SYN condition, implying a prominent role for this area in Chinese syntactic processing.

As compared with Chen's (1999) study, in which both pure semantic violations and semantic + syntactic violations were found to be evident in the region following the $\mathrm{CW}$, the present study demonstrated that the effect of these violations occurred right on the $\mathrm{CW}$. In addition, differences between the effects of semantic and semantic + syntactic violations were observed in subsequent regions after the CW in our study, but not in Chen's (1999). The reason why our results differed from Chen's (1999) may have to do with the paradigms employed; whereas Chen (1999) used a character-by-character self-paced reading procedure, we used the eyetracking procedure, a more natural and elaborate technique. Furthermore, these differences support the view that eye movement recording is sensitive to differences in levels of sentence processing and, thus, allows researchers to better understand the integration process during language comprehension.

Our results are also different from two recent ERP studies on Chinese semantic and syntactic processing (Ye et al., 2006; Yu \& Zhang, 2008). On the one hand, Ye et al. suggested that syntactic processing appears earlier than semantic processing. However, the results of Ye et al.'s study may have been due to the special manipulation of their pure syntactic violation. Given that the $\mathrm{CW}$ in a sentence was a verb, the NP of a preposition-object phrase structure prior to this verb was eliminated in the syntactic violation condition, whereas the NP was preserved with the target verb and altered to be semantically inconsistent with the sentential context in the semantic violation condition. The number of characters prior to the target verb was not equal between these two conditions, and the syntactic violation effects observed on the $\mathrm{CW}$ (a verb) could be confounded by the effects of the missing NP. Moreover, it is not clear that there was no semantic violation in Ye et al.'s syntactic condition as a result of the missing NP, which could cause an even more severe semantic violation and, thus, trigger an earlier violation effect than the pure semantic violation condition.

On the other hand, in Yu and Zhang's (2008) study, the difference between the semantic and the semantic+syntactic violation was evident only in the 300 - to 500 -msec time window (N400), since the combined violations yielded larger negativity than did the semantic violation, whereas in the 550- to 800-msec time window, the component $\mathrm{P} 600$ (which reflects syntactic processing and later semantic integration) did not reveal a different pattern of effects between the two violation conditions. In contrast, our results demonstrated significant differences between the two violation conditions in first-pass indices, as well as indices reflecting later processing in the target region and the region following it. The different pattern of results between our study and that of Yu and Zhang's is also related to the research technique employed. Although both ERP and eye movement experiments can reflect momentto-moment cognitive processes, there is evidence that the eye movement data are not always consistent with ERP 
data. For example, the N400, which is widely accepted to reflect semantic processing, appears about $400 \mathrm{msec}$ after the onset of the stimuli. But by $400 \mathrm{msec}$, the eyes will have already moved on to a following word (Sereno \& Rayner, 2003). And as indicated in our experiment, a semantic violation could be detected right on the $\mathrm{CW}$ within a $250-\mathrm{msec}$ fixation duration. Therefore, it is not reasonable to directly compare the results from studies using different research techniques, and more research is needed to determine the theoretical significance of the findings from different paradigms.

Overall, the present research indicates that despite great differences between Chinese and alphabetic writing systems, there are still many similarities in sentence processing between them. First, both semantic and syntactic violations can be detected immediately, although Chinese is considered to be a highly context-dependent language. Second, although a syntactic violation is always accompanied by a semantic violation, evidence from eyetracking data confirms that syntactic violations yield more severe disruption than do pure semantic violations. However, we have to point out that these results may be dependent on the experimental manipulation in the present study, in which the context prior to the $\mathrm{CW}$ may have encouraged readers to develop an expectation of the word category of the CW (a noun). If the prior context was insufficient for readers to guess the word category of the $\mathrm{CW}$, the violation effect may have been delayed. However, in that case, it would not be certain that the manipulation of semantic and/or syntactic violations was effective. Further studies will be needed to elucidate the finer processing of semantic and syntactic information in the reading of Chinese. The present study at least indicates that these two types of processing can be initiated immediately and dissociated from each other under certain conditions.

Nevertheless, there is also evidence for languagespecific characteristics in the reading of Chinese in our study, in that syntactic processing did not start in advance of semantic processing. This points out the importance of conducting research across languages. Similar studies will help to explore both universal and language-specific processes associated with the processing of different writing systems and, furthermore, will help to build a genuinely comprehensive theory of human language processing during reading.

\section{AUTHOR NOTE}

This research was based on the first author's master's thesis at the South China Normal University under the guidance of the second author. Preparation of the article was supported by grants from the National Natural Science Foundation of China (30670700), the Guangdong Natural Science Foundation, China (06200524), and the Program for New Century Excellent Talent in Universities in China (NCET-08-0645) to the second author, by Grant CUHK441008 from the Research Grants Council of the Hong Kong Special Administrative Region, China, to the third author, and by Grant HD26765 from the National Institutes of Health to the fourth author. We thank Yimin Xu, Lan Chen, and Xiuhong Tong for their help with data collection. Correspondence concerning the article should be sent to S. Wang, Department of Psychology, South China Normal University, Guangzhou 510631, China (e-mail: suipingscnu@263.net).

\section{REFERENCES}

Aaronson, D., \& Ferres, S. (1986). Sentence processing in ChineseAmerican bilinguals. Journal of Memory \& Language, 25, 136-162. doi:10.1016/0749-596X(86)90026-4

BAAYEN, R. H. (2008). Analyzing linguistic data: A practical introduction to statistics using $R$. Cambridge: Cambridge University Press.

BaAyen, R. H., Davidson, D. J., \& Bates, D. M. (2008). Mixedeffects modeling with crossed random effects for subjects and items. Journal of Memory \& Language, 59, 390-412. doi:10.1016/j .jml.2007.12.005

BADER, M., \& LASSER, I. (1994). German verb-final clauses and sentence processing: Evidence for immediate attachment. In C. Clifton, Jr., L. Frazier, \& K. Rayner (Eds.), Perspectives on sentence processing (pp. 225-242). Hillsdale, NJ: Erlbaum.

Bates, D. M., Maechler, M., \& DaI, B. (2008). Ime4: Linear mixedeffect models using S4 classes. R package version 0.999375-1 [Software]. Vienna: R Foundation for Statistical Computing.

Birch, S., \& RAYNER, K. (1997). Linguistic focus affects eye movements during reading. Memory \& Cognition, 25, 653-660.

BoLAND, J. E. (1997). The relationship between syntactic and semantic processes in sentence comprehension. Language \& Cognitive Processes, 12, 423-484. doi:10.1080/016909697386808

Braze, D., Shankweiler, D., Ni, W., \& Palumbo, L. C. (2002). Readers' eye movements distinguish anomalies of form and content. Journal of Psycholinguistic Research, 31, 25-44.

Снао, Y. R. (1968). A grammar of spoken Chinese. Berkeley: University of California Press.

Chen, H.-C. (1992). Reading comprehension in Chinese: Some implications from character reading times. In H.-C. Chen \& O. Tzeng (Eds.), Language processing in Chinese (pp. 175-205). Amsterdam: NorthHolland.

Chen, H.-C. (1996). Chinese reading and comprehension: A cognitive psychology perspective. In M. H. Bond (Ed.), Handbook of Chinese psychology (pp. 43-62). Hong Kong: Oxford University Press.

CHEN, H.-C. (1999). How do readers of Chinese process words during reading for comprehension? In J. Wang, A. W. Inhoff, \& H.-C. Chen (Eds.), Reading Chinese script: A cognitive analysis (pp. 257-278). Mahwah, NJ: Erlbaum.

Chen, H.-C., \& Juola, J. F. (1982). Dimensions of lexical coding in Chinese and English. Memory \& Cognition, 10, 216-224.

Chen, H.-C., \& ShU, H. (2001). Lexical activation during the recognition of Chinese characters: Evidence against early phonological activation. Psychonomic Bulletin \& Review, 8, 511-518.

Chen, H.-C., Song, H., Lau, W. Y., Wong, K. F. E., \& Tang, S. L. (2003). Developmental characteristics of eye movements in reading Chinese. In C. McBride-Chang \& H.-C. Chen (Eds.), Reading development in Chinese children (pp. 157-169). Westport, CT: Praeger.

Chen, H.-C., \& Zhou, X. (1999). Processing East Asian languages: An introduction. Language \& Cognitive Processes, 14, 425-428. doi:10.1080/016909699386130

Cheung, H., Chen, H.-C., LaI, C. Y., Wong, O. C., \& Hills, M. (2001). The development of phonological awareness: Effects of speech experience, orthography, and literacy. Cognition, 81, 227-241. doi:10.1016/ S0010-0277(01)00136-6

Crocker, M. W. (1994). On the nature of the principle-based sentence processor. In C. Clifton, Jr., L. Frazier, \& K. Rayner (Eds.), Perspectives on sentence processing (pp. 245-266). Hillsdale, NJ: Erlbaum.

Cutler, A., \& OtaKe, T. (1994). Mora or phoneme? Further evidence for language-specific listening. Journal of Memory \& Language, 33, 824-844. doi:10.1006/jmla.1994.1039

DANKs, J. H. (1986). Identifying component processes in reading: Comment on Haberlandt and Graesser. Journal of Experimental Psychology: General, 115, 198-200.

DanKs, J. H., BoHN, L., \& Fears, R. (1983). Comprehension processes in oral reading. In G. B. Flores d'Arcais \& R. J. Jarvella (Eds.), The process of language understanding (pp. 193-223). Chichester, U.K.: Wiley.

Drieghe, D., Rayner, K., \& Pollatsek, A. (2008). Mislocated fixations can account for parafoveal-on-foveal effects in eye movements during reading. Quarterly Journal of Experimental Psychology, 61, 1239-1249. doi:10.1080/17470210701467953 
Duffy, S. A., Morris, R. K., \& RAYner, K. (1988). Lexical ambiguity and fixation times in reading. Journal of Memory \& Language, 27, 429-446. doi:10.1016/0749-596X(88)90066-6

Ehrlich, K., \& RAYNer, K. (1983). Pronoun assignment and semantic integration during reading: Eye movements and immediacy of processing. Journal of Verbal Learning \& Verbal Behavior, 22, 75-87.

FAN, X. (2007). Regularity and flexibility of grammatical constructions. Hanyu Xuexi [Chinese Language Learning], 158, 3-11.

Feng, G., Miller, K., Shu, H., \& Zhang, H. (2001). Rowed to recovery: The use of phonological and orthographic information in reading Chinese and English. Journal of Experimental Psychology: Learning, Memory, \& Cognition, 27, 1079-1100. doi:10.1037/0278 $-7393.27 .4 .1079$

FRAZIER, L., \& RAYNER, K. (1982). Making and correcting errors during sentence comprehension: Eye movements in the analysis of structurally ambiguous sentences. Cognitive Psychology, 14, 178-210.

Friederici, A. D., Pfeifer, E., \& Hahne, A. (1993). Event-related brain potentials during natural speech processing: Effects of semantic, morphological and syntactic violations. Cognitive Brain Research, 1, 183 192. doi:10.1016/0926-6410(93)90026-2

Gandour, J., Wong, D., Lowe, M., Dzemidzic, M., SatthamNUWOng, N., Tong, Y., \& LI, X. (2002). A cross-linguistic fMRI study of spectral and temporal cues underlying phonological processing. Journal of Cognitive Neuroscience, 14, 1076-1087. doi:10.1162/089892902320474526

Gunter, T. C., Stowe, L., \& Mulder, G. (1997). When syntax meets semantics. Psychophysiology, 34, 660-676.

Hahne, A., \& Friederici, A. D. (2002). Differential task effects on semantic and syntactic processes as revealed by ERPs. Cognitive Brain Research, 13, 339-356. doi:10.1016/S0926-6410(01)00127-6

Just, M. A., \& CARPenter, P. A. (1980). A theory of reading: From eye fixations to comprehension. Psychological Review, 87, 329-354.

Kambe, G., Rayner, K., \& Duffy, S. A. (2001). Global context effects on processing lexically ambiguous words: Evidence from eye fixations. Memory \& Cognition, 29, 363-372.

LiU, Y. (1990). Xiandai Hanyu changyongci cipin cidian [Modern Chinese word frequency dictionary]. Beijing: Yuhang Press.

Magliano, J. P., Graesser, A. C., Eymard, L. A., Haberlandt, K., \& GHolson, B. (1993). Locus of interpretive and inference processes during text comprehension: A comparison of gaze durations and word reading times. Journal of Experimental Psychology: Learning, Memory, \& Cognition, 19, 704-709. doi:10.1037/0278-7393.19.3.704

McElree, B., \& Griffith, T. (1995). Syntactic and thematic processing in sentence comprehension: Evidence for a temporal dissociation. Journal of Experimental Psychology: Learning, Memory, \& Cognition, 21, 134-157.

Nuthmann, A., Engbert, R., \& Kliegl, R. (2005). Mislocated fixations during reading and the inverted optimal viewing position effect Vision Research, 45, 2201-2217. doi:10.1016/j.visres.2005.02.014

RAYNER, K. (1998). Eye movements in reading and information processing: 20 years of research. Psychological Bulletin, 124, 372-422.

Rayner, K., CooK, A. E., Juhasz, B. J., \& Frazier, L. (2006). Immediate disambiguation of lexically ambiguous words during reading: Evidence from eye movements. British Journal of Psychology, 97, 467-482. doi:10.1348/000712605X89363

RAYNER, K., \& DufFy, S. A. (1986). Lexical complexity and fixation times in reading: Effects of word frequency, verb complexity, and lexical ambiguity. Memory \& Cognition, 14, 191-201.

Rayner, K., \& Frazier, L. (1989). Selection mechanisms in reading lexically ambiguous words. Journal of Experiment Psychology: Learning, Memory, \& Cognition, 15, 779-790.

RAYNER, K., \& Juhasz, B. J. (2004). Eye movements in reading: Old questions and new directions. European Journal of Cognitive Psychology, 16, 340-352. doi:10.1080/09541440340000385

Rayner, K., \& PollatseK, A. (1989). The psychology of reading. Englewood Cliffs, NJ: Prentice Hall.

Rayner, K., Warren, T., Juhasz, B. J., \& Liversedge, S. P. (2004). The effect of plausibility on eye movements in reading. Journal of Experimental Psychology: Learning, Memory, \& Cognition, 30, 12901301. doi:10.1037/0278-7393.30.6.1290

Rayner, K., White, S. J., Kambe, G., Miller, B., \& Liversedge, S. P. (2003). On the processing of meaning from parafoveal vision during eye fixations in reading. In J. Hyönä, R. Radach, \& H. Deubel (Eds.),
The mind's eye: Cognitive and applied aspects of eye movements (pp. 213-234). Amsterdam: Elsevier.

R Development Core Team (2008). R: A language and environment for statistical computing. Vienna: R Foundation for Statistical Computing. Available at www.R-project.org.

Rösler, F., Pütz, P., Friederici, A. D., \& Hahne, A. (1993). Eventrelated brain potentials while encountering semantic and syntactic constraint violations. Journal of Cognitive Neuroscience, 5, 345-362. doi:10.1162/jocn.1993.5.3.345

Schirmer, A., Tang, S.-L., Penney, T. B., Gunter, T. C., \& Chen, H.-C. (2005). Brain responses to segmentally induced semantic violations in Cantonese. Journal of Cognitive Neuroscience, 17, 1-12. doi:10.1162/0898929052880057

Sereno, S. C., O'Donnell, P., \& Rayner, K. (2006). Eye movements and lexical ambiguity resolution: Investigating the subordinate bias effect. Journal of Experimental Psychology: Human Perception \& Performance, 32, 335-350. doi:10.1037/0096-1523.32.2.335

Sereno, S. C., \& RAYNer, K. (2003). Measuring word recognition in reading: Eye movements and event-related potentials. Trends in Cognitive Sciences, 7, 489-493. doi:10.1016/j.tics.2003.09.010

SHI, D. X. (2000). The flexibility of Chinese syntax and the theory of syntax. Dangdai Yuyanxue [Contemporary Linguistics], 2, 18-26.

STARR, M. S., \& RAYNER, K. (2001). Eye movements during reading: Some current controversies. Trends in Cognitive Sciences, 5, 156-163. doi:10.1016/S1364-6613(00)01619-3

Sturt, P., \& Crocker, M. (1996). Monotonic syntactic processing: A cross-linguistic study of attachment and reanalysis. Language \& Cognitive Processes, 11, 449-494. doi:10.1080/016909696387123

Van Berkum, J., Hagoort, P., \& Brown, C. M. (1999). Semantic integration in sentences and discourse: Evidence from the N400. Journal of Cognitive Neuroscience, 11, 657-671. doi:10.1162/ 089892999563724

WAng, S., Chen, H.-C., YAng, J., \& Mo, L. (2008). Immediacy of integration in discourse comprehension: Evidence from Chinese readers' eye movements. Language \& Cognitive Processes, 23, 241-257. doi:10.1080/01690960701437061

Wang, S., Zhu, Z., Wang, Z., Zhang, J. X., Xiao, Z., Xiang, H., \& CHEN, H.-C. (2008). Broca's area plays a role in syntactic processing during Chinese reading comprehension. Neuropsychologia, 46, 13711378. doi:10.1016/j.neuropsychologia.2007.12.020

Wong, K. F. E., \& CHEN, H.-C. (1999). Orthographic and phonological processing in reading Chinese. Language \& Cognitive Processes, 14, 461-480. doi:10.1080/016909699386158

Yan, M., Richter, E., Shu, H., \& Kliegl, R. (2009). Readers of Chinese extract semantic information from parafoveal words. Psychonomic Bulletin \& Review, 16, 561-566. doi:10.3758/PBR.16.3.561

YANG, J., WANG, S., XU, Y., \& RAYNER, K. (2009). Do Chinese readers obtain preview benefit from character $n+2$ ? Evidence from eye movements. Journal of Experimental Psychology: Human Perception \& Performance, 35, 1192-1204. doi:10.1037/a0013554

Ye, Z., Luo, Y.-J., Friederici, A. D., \& Zhou, X. (2006). Semantic and syntactic processing in Chinese sentence comprehension: Evidence from event-related potentials. Brain Research, 1071, 186-196. doi:10.1016/j.brainres.2005.11.085

Yen, M.-H., Tsai, J.-L., Tzeng, O. J. I., \& Hung, D. L. (2008). Eye movements and parafoveal word processing in reading Chinese. Memory \& Cognition, 36, 1033-1045. doi:10.3758/MC.36.5.1033

YU, J., \& ZHANG, Y. (2008). When Chinese semantics meets failed syntax. NeuroReport, 19, 745-749. doi:10.1097/WNR.0b013e3282fda21d

ZHANG, L. (1997a). Issue on semantic categories. Hanyu Xuexi [Chinese Language Learning], 100, 8-13.

ZHANG, L. (1997b). What is parataxis? Hanyu Xuexi [Chinese Language Learning], 97, 58-61.

\section{NOTES}

1. For more general information about the reading of Chinese and how different it is from alphabetical languages, see Yang, Wang, Xu, and Rayner (2009), Yan, Richter, Shu, \& Kliegl (2009), and Yen, Tsai, Tzeng, and Hung (2008). Although there are differences in the size of the perceptual span between Chinese and English, there is also evidence that lexical processing is similar across the two languages. Here, we will provide only closely related information about the issues addressed 
in the present study, such as the semantic and syntactic properties of Chinese.

2. Whereas words are considered the basic unit of comprehension processes, characters are generally considered the basic unit in perception in Chinese written text. Thus, in the experiment reported here, singlecharacter words were used as target stimuli in order to make sure that semantic and syntactic properties would be manipulated within a basic perception unit.

3. There were originally 48 experimental sentences. However, an anonymous reviewer pointed out that in some of our congruent sentences, the $\mathrm{CW}$ and the character to its left $(\mathrm{CW}-1)$ could be a modified $\mathrm{NP}$ within a compound word/phrase including $\mathrm{CW}-1, \mathrm{CW}, \mathrm{CW}+1$, and $\mathrm{CW}+2$. To deal with this, we eliminated eight problematic items and one good item (to counterbalance the three conditions). In the remaining 39 sentences, $\mathrm{CW}-1$ and the $\mathrm{CW}$ formed a $\mathrm{VO}$ (verb + object) phrase.
4. The word frequency counts are based on the Xiandai Hanyu Changyongci Cipin Cidian [Modern Chinese Word Frequency Dictionary] (Liu, 1990).

5 . We are grateful to an anonymous reviewer for suggesting this possibility.

6. The reason we combined $\mathrm{CW}-1$ and $\mathrm{CW}$, rather than $\mathrm{CW}$ and $\mathrm{CW}+1$, as the target region $\mathrm{T}$ is that we did not want to mix up the effects of violation on $\mathrm{CW}+1$ (which was a little bit delayed) with those on $\mathrm{CW}$.

7. A contrast between the CON and SEM+SYN conditions was not set up largely because the SEM + SYN condition includes a semantic violation that is, in principle, equivalent to the SEM condition. If a significant difference was observed between the SEM and CON conditions, there should also be a significant difference between the $\mathrm{CON}$ and SEM + SYN conditions. However, it would be hard to tell whether this difference is due to semantic or syntactic processing.

\section{APPENDIX}

Experimental Sentences, With the Critical Words in Bold, in the CON, SEM, and SEM+SYN Conditions (English Translations Are Provided Below the Sentences)

1 划木舟渡江/钢/伸大概需要一天一夜的时间。 Rowing a wooden boat across the river/steel/stretch probably requires a day and night.

2 小李经常饮酒/枪/挂因此容易患上胃炎等疾病。 Xiao Li drinks a lot of wine/gun/hang so he could easily get stomach illness.

3 陆星常遇见扫街/湖/推的女人到那个菜场去买东西。 Lu Xing often saw the woman who sweeps the streets/lake/push do shopping in that market.

4 刘灿回家都要脱鞋/墙/碰才进房间确保地板干净。

Liu Chan always takes off his shoes/wall/touch before entering the room to keep the floor clean.

5 爷爷喜欢边喝茶/货/养边和朋友一起下棋聊天。 Grandpa likes drinking tea/goods/feed while he is playing chess with his friends.

6 妈妈习惯一边穿衣/血/求一边琢磨怎么搭配才有新意。 My mom often thinks how to wear in a fashion style when she puts on clothes/blood/beg.

7 刘庸天天爬楼/球/躲是因为他将此当作一种运动。 Liu Yong climbs the stairs/ball/hide everyday because he considers it good exercise.

8 有时用农药杀虫/牙/夹容易影响作物的生长周期。 Sometimes using pesticide to kill pests/tooth/clip can affect crops' growing cycle.

9 骑自行车爬坡/诗/扔一会儿就使人感到很疲忞。 It is easy to get tired when you are biking up a hillside/poem/throw.

10 阿姨去买盐/客/染和肉准备腌制腊肠过春节。 Aunt bought salt/guest/dye to make sausage for Spring Festival.

11 冬天给孩子戴帽/狼/割可以保护头部不易受凉。 In winter, wearing hats/wolf/cut can protect children from catching a cold.

12 老王每天都要挤奶/竹/扫送到农场里的便利店卖。 Mr. Wang needs to take milk/bamboo/sweep and send it to the farm's store every day.

13 赵伟认为捕虎/庙/逗是件极端危险而刺激的事情。 Zhao Wei considers hunting tigers/temple/tease extremely dangerous and exciting.

14 农村人喜欢捉蝉/裤/催那是因为它们可以入药。 Countrymen like catching cicadas/trousers/hurry because they can be used as medicine.

15 老人一直以宰猫/绳/抖赚取生活费来供养小孙子。 The old man butchers cats/rope/tremble for people to make money for raising his grandson.

16 王强平常以写稿/稻/燃作为爱好而非糊口的手段。 Wang Qiang usually writes articles/rice/burn for fun but not for money.

17 工人们正在铺砖/铃/毁准备扩建小区里的花坛。 Workers are paving bricks/bell/destroy to extend the flowerbed in the community.

18 王武常常一边煮汤/炉/拆一边看精彩的连环小说。 Wang Wu usually reads novels during the time the soup/stove/disconnect is boiling.

19 小明下午洗缸/峰/跃准备将新买的金鱼放进去。 Xiao Ming washed the tank/peak/jump for the newly bought fish in the afternoon.

20 王芳觉得吃桃/铅/挣之后胃就有些不太舒服。 Wang Fang has a stomach upset after she ate some peaches/lead/earn.

21 农民准备割麦/巷/吞后种一些青菜到集市去卖。 The farmers plan to grow vegetables after they harvest the wheat/lane/swallow.

22 水灾使筑坝/椅/捡成为迫切需要解决的问题。 Floods make it an urgent problem to construct dams/chair/pick.

23 小妹生气就会摔碗/殿/瞒或者扔枕头来发泄情绪。 Little sister breaks (drops) bowls/palace/conceal or pillows to release her anger. 


\section{APPENDIX (Continued)}

24 吴铭和同学赶驴/柱/卧从山上运货物到城里卖。 Wu Ming and his classmates ride donkeys/pillar/lie to transport goods from mountains to cities.

25 叉烧肉淋蜜/墓/攀之后就有一种独特的风味。 Serving barbecued pork with honey/tomb/climb makes a special flavor.

26 肖明喜欢攀崖/妻/轰这种极少人敢挑战的运动。 Xiao Ming is fond of challenging sports like climbing cliff/wife/boom that few people dare to practice.

27 很多农村家庭举债/绸/烘以供孩子去城里读大学。 Many rural families get into debt/silk/bake to support their children's education in college.

28 老板给大家提薪/桑/瞥庆祝公司成立五十周年。

The boss raised his employees' salary/mulberry/glance to celebrate the 50th anniversary of the company's foundation.

29 小明周末采苯/亭/奉 卖给小贩以赚点小钱。 Xiao Ming made some money by picking dates/pavilion/devote and selling them to peddlers.

30 吴旭喜欢下棋/蹄/援因为这有助于修身养性。 Wu Xu likes playing chess/hoof/help because it helps to cultivate people's personality.

31 古代官员都以乘轿/祸/耕代替步行从而显示排场。 Ancient officers all ride in sedans-chairs/disaster/cultivate instead of walking to show off their power.

32 那艘大船扬帆柜/创离开了这一个热闹的港口。 That big ship put up the sails/cabinet/create and left the busy harbor.

33 小吴周末喜欢买碟/湾/硚回家看而不太喜欢去电影院。 Xiao Wu usually buys movies/bay/lick and watches them at home during the weekend.

34 老李家用饲料喂猪/针/歇之后生产效益大大提高了。 Mr. Li received beneficial results after he starts feeding pigs/needle/rest with fodders.

35 老人很早就上炕/浪/拣等着儿子给他打电话。 The old man went to Kang (a kind of bed)/wave/pick early and waited for his son's call.

36 小芳是个容易流泪/碑/钓但是胆子却很大的孩子。 Xiao Fang shed tears/monument/fishing easily but she is actually a courageous girl.

37 他们每年都要修渠/柴/跪和做好相关的防洪工作。 They need to check and repair ditches/firewood/kneel every year in case of floods.

38 小红正在给吃梨/窉/袭的爸爸解释这水果的药性。 When her father was eating a pear/curtain/attack, Xiao Hong explained to him about its medical properties.

39 老张每天獒药/窗/忘给他身体虚弱的母亲喝。 Mr. Zhang boils herbs/window/forget for his sick mom every day. 